\title{
Monitoring Impact of Salt-Marsh Vegetation Characteristics on Sedimentation: an Outlook for Nature-Based Flood Protection
}

\author{
B. Martina Baaij ${ }^{1,2}$ (D) Jeroen Kooijman ${ }^{2} \cdot$ Juul Limpens $^{1}$ (D) - Richard J. C. Marijnissen ${ }^{2}$ (D) \\ Jantsje M. van Loon-Steensma ${ }^{2}$ (B)
}

Received: 10 December 2020 / Accepted: 27 May 2021 / Published online: 1 July 2021

(C) The Author(s) 2021

\begin{abstract}
Salt marshes can protect coastlines against flooding by attenuating wave energy and enhancing shoreline stabilization. However, salt-marsh functioning is threatened by human influences and sea level rise. Although it is known that protection services are mediated by vegetation, little is known about the role of vegetation structure in salt-marsh accretion. We investigated the role of vegetation presence, vegetation type and structural vegetation characteristics in sedimentation and sediment grain size. We established 56 plots on a salt marsh on the Dutch Wadden island of Texel. Plots were divided over four vegetation types contrasting in vegetation structure and varied in elevation and distance to creeks. Vegetation presence was controlled by clipping in subplots. Within each plot, we measured seven vegetation characteristics, sedimentation and the sediment grain size distribution. Furthermore, we explored the effect of the natural variation in vegetation structure on wave attenuation with a simple model approach. For this, we developed vegetation scenarios based on the field measurements of stem height, diameter and density. We found that vegetation presence increased sedimentation on average by $42 \%$. Sedimentation was highest in Salicornia vegetation and increased with stem height and branching level. Grain size also seemed to increase with branching level. Modelled wave attenuation was 7.5 times higher with natural vegetation compared to topography only, was strongest for Spartina vegetation and most sensitive to the natural variance in stem density. Our results can be used to improve predictions of salt-marsh accretion and the implementation of salt marshes in nature-based flood defences.
\end{abstract}

Keywords Vegetation type $\cdot$ Vegetation structure $\cdot$ Biomass $\cdot$ Sediment deposition $\cdot$ Wave damping $\cdot$ Grain size

\section{Introduction}

Salt marshes provide important ecosystem services, such as protection against coastal erosion and flooding (Gedan et al. 2009; Barbier et al. 2011). However, salt marshes are threatened worldwide by changes in land use and climate, leading to salt-marsh degradation and the loss of ecosystem services (Adam 2002; Gedan et al. 2009). Salt marshes are expected

Juul Limpens

juul.limpens@wur.nl

$\triangle$ Jantsje M. van Loon-Steensma

jantsje.vanloon@wur.nl

1 Plant Ecology and Nature Conservation Group, Wageningen University \& Research, P.O. Box 47, Wageningen 6700 AA, The Netherlands

2 Water Systems and Global Change Group, Wageningen University \& Research, P.O. Box 47, Wageningen 6700 AA, The Netherlands to drown from sea level rise when landward migration is blocked by steep slopes or barriers (Torio and Chmura 2013), or when relative sea level rise exceeds accretion rates (Redfield 1965). Crosby et al. (2016) predicted that 60-91\% of their studied salt marshes are threatened by sea level rise, based on the sea-level rise scenarios predicted by the Intergovernmental Panel on Climate Change (IPCC) for 2100 (Stocker et al. 2013). However, salt-marsh vulnerability to sea level rise may be exaggerated without consideration of biophysical feedbacks between plant growth and accretion (Kirwan and Megonigal 2013; Crosby et al. 2016; Kirwan et al. 2016).

The expected sea level rise and increased storm activity highlights the role of salt marshes in coastal protection (Shepard et al. 2011; Leonardi et al. 2018). A meta-analysis by Shepard et al. (2011) demonstrates positive contributions of salt-marsh vegetation to shoreline stabilization (i.e. sediment deposition, prevention of erosion and increase in elevation) and wave attenuation. Wave attenuation can be observed 
even during storm conditions (Möller et al. 2014; Vuik et al. 2016; Garzon et al. 2019a). Temmerman et al. (2013) therefore argue that coastal ecosystems, like salt marshes, are a preferable long-term flood protection measure over conventional hard infrastructure because of their natural adaptive capacity to sea level rise. However, the implementation of salt marshes in nature-based solutions requires an in-depth understanding of the role of vegetation in their adaptive capacity and flood protection function.

Vegetation enhances the settling of sediment and prevents erosion by reducing the flow velocity and turbulence between stems and by wave attenuation (Möller et al. 1999; Christiansen et al. 2000; Shi et al. 2012; Möller et al. 2014). Furthermore, vegetation itself can trap suspended sediment by adhesion of the sediment particles (Li and Yang 2009). Sedimentation and wave attenuation are influenced by vegetation characteristics like height, density, biomass and stiffness of the vegetation (e.g., Bouma et al. 2010; Shepard et al. 2011; Anderson and Smith 2014; Reef et al. 2018).

When studying the role of vegetation in the adaptive capacity and flood protection function of salt marshes, geomorphological factors must be taken into account, as they influence sediment deposition, wave attenuation and vegetation growth (e.g., Möller et al. 1999; Wood and Hine 2007; Townend et al. 2011). Sedimentation decreases with a larger distance to the source of sediment, such as the sea or a creek, due to the progressive settlement of sediment out of suspension (e.g., Reed et al. 1999; Wood and Hine 2007). More elevated locations experience less inundation and thus accumulate less sediment (e.g., Townend et al. 2011; Reef et al. 2018). Also the sediment grain size generally decreases with elevation and distance to the source of sediment, due to a reduction of wave action, flow velocity and turbulence (Yang 1999a; Yang et al. 2000; Yang et al. 2008; Gibeault et al. 2016). Wave energy diminishes with elevation due to wave breaking in shallow water and friction with the foreshore (e.g., Möller et al. 1999; Möller 2006; Ysebaert et al. 2011). Furthermore, elevation, inundation frequency and distance to the creek also influence plant species occurrence, resulting in vegetation zonation (Adam 2002; Townend et al. 2011).

Studies investigating the impact of vegetation on sedimentation or wave attenuation have focussed on a limited number of plant species (e.g., often Spartina species) (for an overview of studies see Shepard et al. (2011) or Vuik et al. (2016)). Elevation differences between vegetated and unvegetated sites complicate studying the effect of vegetation presence (Möller et al. 1999; Shepard et al. 2011). A limited number of field studies have investigated the effect of vegetation characteristics on sediment deposition and sediment grain size (Morris et al. 2002; Yang et al. 2008; Gibeault et al. 2016; Reef et al. 2018). These studies primarily focus on the density, height or biomass of the vegetation (Shepard et al. 2011). Studies investigating the effect of vegetation characteristics on wave attenuation mainly focus on the density, height or stiffness of the vegetation (Augustin et al. 2009; Shepard et al. 2011; Anderson and Smith 2014; Peruzzo et al. 2018). This effect is often studied in flume experiments with artificial or real vegetation (Augustin et al. 2009; Anderson and Smith 2014; Peruzzo et al. 2018). However, the relative importance of each vegetation characteristic to wave attenuation (Anderson and Smith 2014) and their variation in the field require further investigation.

In this paper, we investigated the effect of vegetation presence, vegetation type and natural variation in vegetation structure characteristics on sedimentation and sediment grain size on a salt marsh in the Netherlands. Additionally, we developed field-based vegetation scenarios to explore the potential effect of natural variations in vegetation characteristics on wave attenuation with a simple model approach. In the field, a total of 56 plots were established in four vegetation types and over a range of elevations and distances to the creek. Vegetation presence was controlled and seven vegetation characteristics (total cover, vegetation height, stem height, stem diameter, branching level, stem density and biomass), sedimentation and the sediment grain size distribution were measured. For this field experiment, we expected (1) vegetation presence to increase sedimentation, (2) to observe differences in sedimentation and sediment grain size between vegetation types and (3) effects of vegetation characteristics on sedimentation and sediment grain size. Subsequently, vegetation scenarios were developed based on the field measurements of three vegetation characteristics (stem height, stem diameter and stem density) to model wave height with the XBeach 1D model over a transect. With this established model we aimed to explore (1) how modelled wave attenuation by vegetation zonation (i.e. the field situation) compares to the absence of vegetation, (2) how modelled wave attenuation differs between the four vegetation types and (3) how modelled wave attenuation is affected by natural variance of vegetation characteristics.

\section{Methods}

\section{Study Area}

All field research was conducted on a salt marsh in nature reserve the Slufter on the barrier island of Texel, the Netherlands $\left(53^{\circ} 08^{\prime} 18.4^{\prime \prime} \mathrm{N}, 4^{\circ} 48^{\prime} 31.1^{\prime \prime} \mathrm{E}\right)$ (Fig. 1a, b). The Slufter is managed by the State Forest Service and part of the Natura 2000 network, a European network of protected nature areas. The nature reserve of about 700 ha consists of a dune valley that is surrounded by two sand dikes and connected to the North Sea by a channel (Reitsma and de Jong 2019). The tides are semi-diurnal with a tidal range of $1.7 \mathrm{~m}$ on 


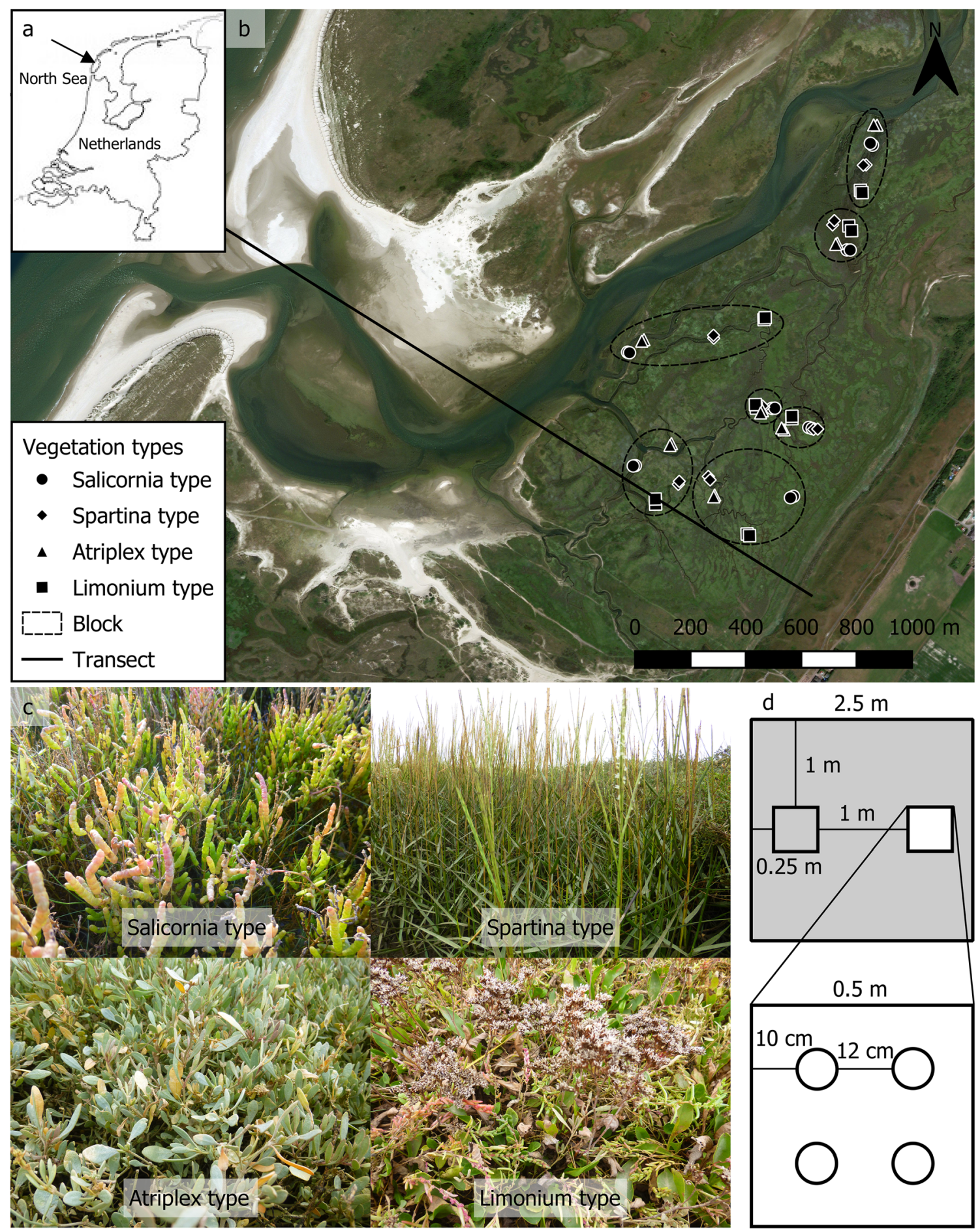

Fig. 1 Study area and design. a Location of study area the Slufter on the barrier island of Texel, the Netherlands. b Aerial view of the Slufter with locations of the 56 plots used for the field experiment, arranged in four vegetation types and seven blocks, and the transect $(5,4 \mathrm{~km})$ used to model wave attenuation. c Overview of the four vegetation types. d

average (between -0.93 and $0.74 \mathrm{~m}+\mathrm{NAP}$; Dutch ordnance level, close to mean sea level), $1.9 \mathrm{~m}$ during spring tides (between -1.08 and $0.82 \mathrm{~m}+\mathrm{NAP}$ ) and $1.3 \mathrm{~m}$ during neap tides (between -0.74 and $0.57 \mathrm{~m}+\mathrm{NAP}$ ).
Schematic representation on the left of a plot with two subplots where vegetation is present (grey) or removed (white) and on the right of a subplot with four sediment traps (circles). Distances are indicated with thin lines

The vegetation in the dune valley of the Slufter consists of a relatively young salt marsh with only a small area of high salt marsh (Reitsma and de Jong 2019). Pioneer vegetation growing along the creeks and in low lying areas is dominated by 
Salicornia species and Suaeda maritima, and some small patches of Spartina anglica are present. Vegetation of the low marsh is dominated by Limonium vulgare and Atriplex portulacoides. The medium salt marsh mainly consists of Festuca rubra, Juncus gerardii, L. vulgare and Plantago maritima. The high salt marsh is dominated by Elytrigia atherica (Reitsma and de Jong 2019).

\section{Study Design of Field Experiment}

The field experiment was conducted between August and October in 2018. 56 plots $(2.5 \times 2.5 \mathrm{~m})$ were established in the Slufter according to a factorial design (Fig. 1b). Plots were made in four vegetation types contrasting in vegetation structure and elevation: vegetation dominated by either Salicornia species (Salicornia type), S. anglica (Spartina type), A. portulacoides (Atriplex type) or L. vulgare (Limonium type) (Fig. 1c; for a schematic representation of the dominating plant species, see Fig. 3a in Möller et al. 1999). Because distance to the source of sediment is known to influence sedimentation (Reed et al. 1999; Temmerman et al. 2003; Wood and Hine 2007), pairs of plots were made near a feeder creek within the same vegetation type. One of the plots within a pair was established at the shortest possible distance to the creek, while the other plot was established at the longest possible distance to the creek. The position relative to the main channel was also expected to influence sedimentation. Therefore, plots were arranged in seven experimental blocks, each block consisting of one pair of plots per vegetation type (Fig. 1b).

In each plot, two subplots $(50 \times 50 \mathrm{~cm})$ were made $1 \mathrm{~m}$ apart and with the same distance to the creek (Fig. 1d). One subplot consisted of intact vegetation, whereas the vegetation in the other subplot was clipped to the soil surface to investigate the effect of vegetation presence on sedimentation. Locations with the same geomorphological factors (e.g., distance to the creek, elevation) but different vegetation could be compared in this setup. The subplots were relatively small to minimize damage to the vegetation of the nature reserve.

The location and elevation were recorded in the centre of the subplots by a Real-Time Kinematic (RTK-)GNNS receiver. The elevation of the plot was determined as the average of the two subplots. The distance to the creek was measured from the centre of the plot to the edge of the creek (transition between vegetation and unvegetated creek).

\section{Vegetation Composition and Characteristics}

The total vegetation cover as well as the cover per plant species were estimated in percentages per plot. Plant species were identified according to van der Meijden (2005). The plant communities in the plots were determined with SynBioSys (Hennekens et al. 2018). This Dutch program contains information on plant species, plant communities and landscapes and has classification software. Vegetation height, defined as the estimated average height of the plant community, was based on measurements in one to three representative locations per plot.

Aside from total cover and vegetation height, five other vegetation characteristics were measured per plot, using the clipped plant material of a representative, smaller area $(10 \times$ $10 \mathrm{~cm}$ ) within the subplot. Only for six plots of the Salicornia type, that had a total cover below $50 \%$, plant material of the whole subplot was used. The number of stems was counted per species to calculate the stem density per square meter. Also the stem height of straightened stems, the stem diameter at around $1 / 3$ of the stem (following van Loon-Steensma et al. 2016) and the branching level of five representative individuals per species were measured. The branching level consisted of the following categories: 1(=stem without branches), 2(=stem with branches), 3(=stem with branched branches), and sometimes $4(=$ stem that is branched three times). When less than five individuals of a species with a cover above $1 \%$ were present, measurements on this species were usually also done on other plant material of the plot. To obtain one value per plot for the stem height, stem diameter and branching level, weighted means were calculated by correcting the average per species for the stem density per species by the following equation:

Weighted mean

$$
=\frac{\sum(\text { average per species*stem density per species })}{\text { stem density per plot }}
$$

This equation is derived from the frequently used calculation of the community weighted mean of plant traits (CWM) (Lavorel et al. 2008). The clipped plant material was dried in a stove at $70{ }^{\circ} \mathrm{C}$ for $48 \mathrm{~h}$ and weighed to calculate the biomass per square meter.

\section{Sedimentation}

Sedimentation was measured over a period of two weeks covering one spring tide in the middle of the study period. Four sediment traps (Reed 1989; Nolte et al. 2013) were placed per subplot in September and secured with iron pegs (Fig. 1d). A sediment trap consisted of an open plastic petri dish (diameter of $9 \mathrm{~cm}$ ) and a filter paper in it. The filter paper was kept in place by wetting it and a small marble on top. During collection of the sediment traps, remaining water in the traps was filtered through new filter paper. Sediment traps and filter papers with sediment were dried in a stove at $60{ }^{\circ} \mathrm{C}$ for $66 \mathrm{~h}$ and weighed (Leonard et al. 1995; Reed et al. 1997). Sedimentation over a period of two weeks was expressed per square meter for each subplot. Storm surge led to a study 
period of eleven and seventeen days for two blocks. This deviation from the original fourteen days was accounted for statistically in the block effect.

\section{Sediment Grain Size}

Samples were taken of the upper $1 \mathrm{~cm}$ of the soil for analysis of the grain size distribution. Two samples were taken from each of the four corners of a plot and mixed. A pre-treatment was performed to a spoon of soil from each plot following the description by Konert and Vandenberghe (1997). Organic material and calcium carbonate were removed with $30 \%$ hydrogen-peroxide $\left(\mathrm{H}_{2} \mathrm{O}_{2}\right)$ and $10 \%$ hydrochloric acid $(\mathrm{HCl})$, respectively. Remaining coarse organic particles and shells were removed by carefully sieving (sieve size of $200 \mu \mathrm{m})$. A Sympatec HELOS/KR Laser Diffraction Machine (range of $0.1-2000 \mu \mathrm{m}$ ) was used to determine the grain size distribution of the pre-treated samples. The median grain size was used from the output for the data analysis.

\section{Data Analysis}

The R software package, version 3.5.1, was used to analyse the data. The data was obtained either at the plot level (distance to the creek, elevation, seven vegetation characteristics, median grain size) or at the subplot level (sedimentation). Differences between the four vegetation types (Salicornia, Spartina, Atriplex, Limonium type) were tested with a oneway ANOVA for elevation and with Kruskal-Wallis rank sum tests for distance to the creek (separately for the short and long distance category) and the seven vegetation characteristics. The tests were followed by a Tuckey HSD post hoc test and multiple comparisons with the package pgirmess (Giraudoux 2018), respectively.

Linear mixed models (LMM) were made with the package nlme (Pinheiro et al. 2018) to test the effect of vegetation on sedimentation and median grain size. The response variables sedimentation and median grain size were always log transformed to meet the model assumptions. First, we tested as fixed effects vegetation presence (present, removed) (only for sedimentation), vegetation type, distance to the creek (short, long) and interactions. The random structure of the models only consisted of random intercepts and was based on the study design: distance to the creek (only for sedimentation) within vegetation type within the random factor block. Final mixed models were obtained after backward model simplification using Likelihood Ratio tests. Multiple comparisons were made for vegetation type using the package multcomp (Hothorn et al. 2008).

Second, we tested the effect of one or two vegetation characteristics on sedimentation and median grain size at a time, while correcting for the most important geomorphological factor and vegetation presence (only for sedimentation). For median grain size, two groups of plots existed with either a low (42 plots, $18.28 \pm 0.83 \mu \mathrm{m}$, mean \pm standard error) or a high median grain size (14 plots, $175.91 \pm 14.24 \mu \mathrm{m}$ ), leading to violation of model assumptions. Therefore, only plots with a low median grain size were used for the response variable median grain size. Elevation was included as fixed effect for sedimentation as it was stronger correlated with sedimentation (Spearman rank correlation, $\rho=-0.49$ ) than distance to the creek (m) $(\rho=-0.27)$, while distance to the creek was included for median grain size as it was stronger correlated with median grain size $(\rho=-0.24)$ than elevation $(\rho=0.15$, Table 1). Interactions were included between two vegetation characteristics and for sedimentation between vegetation presence and the vegetation characteristics. Variables displaying high co-linearity (Spearman rank correlation, $-0.6>\rho>0.6$ ) were not included together in a model (Table 1). The above resulted into six mixed models with one vegetation characteristic and ten mixed models with two vegetation characteristics as fixed effects for sedimentation. For median grain size, seven mixed models with one vegetation characteristic and sixteen mixed models with two vegetation characteristics were made. Stem density was log transformed because of some extreme high values. The random structure of the models for sedimentation was defined as plot within block. Only the random factor block was included for median grain size. The models were ranked based on the Second-order Akaike Information Criterion (AICc) with the package MuMIn (Barton 2018). Backward model simplification was applied to all models with one vegetation characteristic. For the models with two vegetation characteristics, simplification was only applied to the model(s) with the lowest AICc (or similar with a difference $<2$ ). Marginal and conditional pseudo $\mathrm{R}^{2}$ were calculated for the linear mixed models with the package MuMIn (Barton 2018). Statistics are reported for the final models.

\section{Modelling the Potential Influence of Real Vegetation Characteristics on Wave Height with XBeach}

Subsequently, we explored how the observed variation of vegetation characteristics in the field would translate to wave attenuation in XBeach. This numerical model has been developed by Roelvink et al. (2009) and extended by van Rooijen et al. (2016) with vegetation modelled as an energy sink for propagating waves (see Appendix for details). Individual plants are represented by cylinders, and the size, density and drag properties of these cylinders can be adapted to the stem height, diameter, density and stiffness of the plant species studied. After calibration of the bulk drag coefficient, the extended XBeach model can adequately predict wave attenuation (van Rooijen et al. 2016; Garzon et al. 2019a, 2019b).

For this simple exploration, a drag coefficient of 1 was used, although the drag force exerted on the vegetation can 
Table 1 Spearman rank correlations between field measurements on sedimentation or median grain size and elevation, distance to the creek and seven vegetation characteristics. Correlation coefficients smaller than -0.6 or larger than 0.6 are indicated in bold

\begin{tabular}{|c|c|c|c|c|c|c|c|c|c|}
\hline & $\begin{array}{l}\text { Elevation } \\
(\mathrm{m}+\mathrm{NAP})\end{array}$ & $\begin{array}{l}\text { Distance } \\
\text { to creek } \\
\text { (m) }\end{array}$ & $\begin{array}{l}\text { Total } \\
\text { cover }(\%)\end{array}$ & $\begin{array}{l}\text { Vegetation } \\
\text { height }(\mathrm{cm})\end{array}$ & $\begin{array}{l}\text { Stem } \\
\text { height } \\
(\mathrm{cm})\end{array}$ & $\begin{array}{l}\text { Stem } \\
\text { diameter } \\
(\mathrm{mm})\end{array}$ & $\begin{array}{l}\text { Branching } \\
\text { level }\end{array}$ & $\begin{array}{l}\text { Stem } \\
\text { density } \\
\left(\# / \mathrm{m}^{2}\right)\end{array}$ & $\begin{array}{l}\text { Biomass } \\
\left(\mathrm{g} / \mathrm{m}^{2}\right)\end{array}$ \\
\hline $\begin{array}{l}\text { Sedimentation } \\
\left(\mathrm{g} / \mathrm{m}^{2}\right)^{\mathrm{a}}\end{array}$ & -0.49 & -0.27 & -0.25 & 0.27 & 0.25 & 0.36 & 0.12 & -0.36 & 0.09 \\
\hline $\begin{array}{l}\text { Median grain size } \\
(\mu \mathrm{m})^{\mathrm{b}}\end{array}$ & 0.15 & -0.24 & 0.28 & 0.09 & 0.17 & 0.04 & 0.26 & -0.19 & -0.01 \\
\hline $\begin{array}{l}\text { Elevation }(m+ \\
\text { NAP })^{\mathrm{c}}\end{array}$ & - & 0.20 & 0.70 & -0.05 & 0.05 & -0.23 & 0.27 & 0.22 & 0.15 \\
\hline $\begin{array}{l}\text { Distance to creek } \\
(\mathrm{m})^{\mathrm{c}}\end{array}$ & 0.20 & - & -0.06 & -0.05 & -0.11 & 0.05 & 0.06 & -0.03 & 0.02 \\
\hline Total cover $(\%)^{\mathrm{c}}$ & 0.70 & -0.06 & - & 0.28 & 0.42 & 0.07 & 0.46 & 0.15 & 0.53 \\
\hline $\begin{array}{l}\text { Vegetation height } \\
(\mathrm{cm})^{\mathrm{c}}\end{array}$ & -0.05 & -0.05 & 0.28 & - & 0.80 & 0.75 & 0.23 & -0.14 & 0.74 \\
\hline Stem height $(\mathrm{cm})^{\mathrm{c}}$ & 0.05 & -0.11 & 0.42 & 0.80 & - & 0.80 & 0.46 & -0.38 & 0.74 \\
\hline $\begin{array}{l}\text { Stem diameter } \\
(\mathrm{mm})^{\mathrm{c}}\end{array}$ & -0.23 & 0.05 & 0.07 & 0.75 & 0.80 & - & 0.40 & -0.59 & 0.59 \\
\hline Branching level $^{\mathrm{c}}$ & 0.27 & 0.06 & 0.46 & 0.23 & 0.46 & 0.40 & - & -0.51 & 0.39 \\
\hline Stem density $\left(\# / \mathrm{m}^{2}\right)^{\mathrm{c}}$ & 0.22 & -0.03 & 0.15 & -0.14 & -0.38 & -0.59 & -0.51 & - & 0.03 \\
\hline Biomass $\left(\mathrm{g} / \mathrm{m}^{2}\right)^{\mathrm{c}}$ & 0.15 & 0.02 & 0.53 & 0.74 & 0.74 & 0.59 & 0.39 & 0.03 & - \\
\hline
\end{tabular}

${ }^{\mathrm{a}} n=112$

${ }^{\mathrm{b}} n=42$ (only plots with low median grain size)

${ }^{\mathrm{c}} n=56$

vary considerably (Defina and Bixio 2005; Anderson and Smith 2014; Möller et al. 2014; Vuik et al. 2016). While dissipation by vegetation is the main interest of this model exploration, other important dissipation terms across the foreshore were included as well: dissipation by wave breaking (Roelvink 1993), friction, and dissipation by roller energy. Parameters for these processes were kept at the default values of XBeach representing a sandy environment like the Slufter. Other processes of wave energy dissipation or wave energy generation were not included.

We simulated a small storm event within the Slufter comparable to the sheltered environment of the Wadden sea (water level of $2.8 \mathrm{~m}+\mathrm{NAP}$; wave height of $0.9 \mathrm{~m}$, wave period of $5 \mathrm{~s})$. The significant wave height $(\mathrm{Hm} 0)$ was modelled along a 1D transect in the Slufter based on the digital elevation map of the Netherlands (AHN3) (Fig. 1b; Fig. S1, Online Resource). The transect was made through the opening of the Slufter perpendicular to the sand dike eastward of the salt marsh with a length of $5.4 \mathrm{~km}$, of which the last $2.5 \mathrm{~km}$ over the saltmarsh vegetation.

\section{Vegetation Scenarios}

Wave attenuation was modelled for six vegetation scenarios: vegetation absent, Salicornia type, Spartina type, Atriplex type, Limonium type and zonation of the four vegetation types. The first scenario, with only topological data without vegetation, served as a reference to compare vegetation effects. The next four scenarios with one vegetation type were developed to compare the effect of different vegetation types on wave attenuation. The last scenario represents the vegetation in the Slufter.

In each scenario, no vegetation was present below $0.61 \mathrm{~m}+\mathrm{NAP}$, based on the minimum recorded elevation of the plots. In the scenario with four vegetation types, plants representing the Salicornia or Spartina type (pioneer saltmarsh vegetation) both occupied the zones between $0.61 \mathrm{~m}$ and $0.99 \mathrm{~m}+\mathrm{NAP}$, while plants representing the Atriplex or Limonium type (low salt-marsh vegetation) both occupied elevations above $0.99 \mathrm{~m}+\mathrm{NAP}$. This distribution was based on plot elevations recorded in the field. Data on vegetation characteristics of the medium and high salt marsh was not available as plots were not established here during our field experiment.

The values for the stem height, stem diameter and stem density of the plants in the model were based on the mean per vegetation type measured in the field experiment (Fig. 2dg; Table 2). A high variation, as indicated by the large standard error, was observed for the stem density of the Salicornia and Spartina types, because some plots contained a large number of small Puccinellia maritima (Fig. 2g). These extreme densities, that were more than two times larger than the mean, were excluded from calculations of the mean for the model input. 

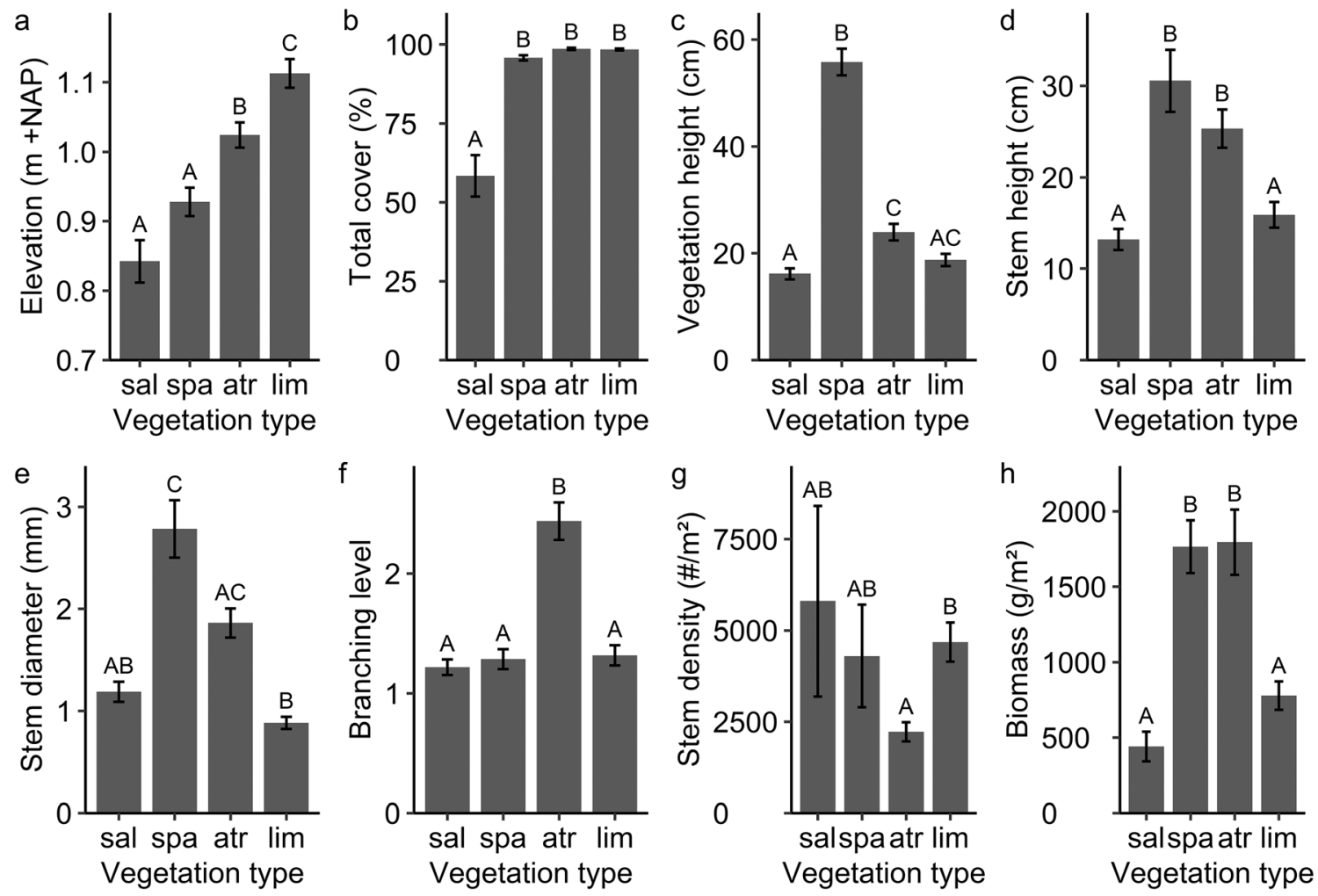

Fig. 2 Means with standard error of the a elevation, b total cover, $\mathbf{c}$ vegetation height, $\mathbf{d}$ stem height, $\mathbf{e}$ stem diameter, $\mathbf{f}$ branching level, $\mathbf{g}$ stem density and $\mathbf{h}$ biomass for the vegetation types Salicornia (sal), Spartina (spa), Atriplex (atr) and Limonium (lim). The capital letters

above the bars indicate significant groups based on a Tuckey HSD post hoc test for the elevation (a) and multiple comparisons after a KruskalWallis rank sum test for the vegetation characteristics (b-h)

Table 2 Overview of the vegetation characteristics used in the vegetation and sensitivity scenarios with the XBeach model and the resulting wave attenuation percentages for the first $100 \mathrm{~m}$ of the saltmarsh vegetation and over the total length of the salt-marsh vegetation

$(2.5 \mathrm{~km})$ for a water level of $2.8 \mathrm{~m}+\mathrm{NAP}$, a wave height of $0.9 \mathrm{~m}$ and a wave period of $5 \mathrm{~s}$. The salt-marsh vegetation occurs in the last $2.5 \mathrm{~km}$ of the transect $(5.4 \mathrm{~km})$

\begin{tabular}{|c|c|c|c|c|c|}
\hline & \multirow[t]{2}{*}{ Stem height $(\mathrm{cm})$} & \multirow[t]{2}{*}{ Stem diameter $(\mathrm{mm})$} & \multirow[t]{2}{*}{ Stem density $\left(\# / \mathrm{m}^{2}\right)$} & \multicolumn{2}{|c|}{ Wave attenuation $(\%)$} \\
\hline & & & & first $100 \mathrm{~m}$ & $2.5 \mathrm{~km}$ \\
\hline \multicolumn{6}{|l|}{ Vegetation scenarios } \\
\hline Vegetation absent & - & - & - & -3.03 & 12.72 \\
\hline Salicornia type & 13.19 & 1.19 & 2128 & 29.30 & 94.92 \\
\hline Spartina type & 30.57 & 2.78 & 2330 & 71.68 & 99.12 \\
\hline Atriplex type & 25.35 & 1.86 & 2222 & 45.41 & 97.35 \\
\hline Limonium type & 15.89 & 0.88 & 4680 & 57.27 & 98.34 \\
\hline Zonation of vegetation types & $\mathrm{a}$ & $\mathrm{a}$ & $\mathrm{a}$ & 59.66 & 98.00 \\
\hline \multicolumn{6}{|l|}{ Sensitivity scenarios } \\
\hline Average scenario & 21.25 & 1.68 & 2887 & 56.84 & 98.31 \\
\hline Min. stem height & 6.85 & 1.68 & 2887 & 29.17 & 94.89 \\
\hline Max. stem height & 60.06 & 1.68 & 2887 & 79.01 & 99.41 \\
\hline Min. stem diameter & 21.25 & 0.60 & 2887 & 31.50 & 95.38 \\
\hline Max. stem diameter & 21.25 & 4.55 & 2887 & 78.01 & 99.37 \\
\hline Min. stem density & 21.25 & 1.68 & 96 & 1.64 & 65.74 \\
\hline Max. stem density & 21.25 & 1.68 & 9288 & 80.79 & 99.47 \\
\hline
\end{tabular}

${ }^{\mathrm{a}}$ The vegetation characteristics of all four vegetation types are applied 


\section{Sensitivity Scenarios}

To explore the influence of natural variance in key vegetation characteristics on modelled wave attenuation, a sensitivity analysis was performed based on the observed variation of vegetation characteristics in the field. Wave attenuation was modelled for seven scenarios, under the same conditions as described before (Table 2). For the baseline scenario, the mean of the stem height, stem diameter and stem density based on all plots was applied to the whole transect above $0.61 \mathrm{~m}+$ NAP. For the other scenarios, one vegetation characteristic was changed at a time, either to the minimum or maximum value of all plots. This analysis will give an indication of the relative influence of natural variations in vegetation characteristics on wave attenuation. The same extreme stem density values as described before were excluded when calculating the mean and maximum stem density. Wave attenuation percentages were calculated over the salt-marsh vegetation for all scenarios based on the significant wave height.

\section{Results}

\section{Plant Species and Communities}

A total of seventeen plant species were identified in the plots (Table S1, Online Resource). Based on the cover percentage of these species, the plots were classified into four different plant communities. All plots of the Salicornia type belonged to the plant community of Salicornietum dolichostachyae. Most of the Spartina type plots were classified as the Spartinetum townsendii plant community. The plots of the Limonium type all belonged to the Plantagini-Limonietum plant community and all the Atriplex type plots belonged to the Halimionetum portulacoides plant community. However, also five plots of the Spartina type were classified as the latter plant community because both $S$. anglica and A. portulacoides had a high cover percentage in these plots.

\section{Comparison of Vegetation Types}

The elevation of the plots differed significantly between the vegetation types (one-way ANOVA: $\mathrm{F}=26.19$, $\mathrm{df}=3$, $p<0.001)$ and increased from the Salicornia type, to the Spartina, Atriplex and Limonium type (Fig. 2a). The distance to the creek was $3.54 \pm 0.56 \mathrm{~m}$ (mean \pm standard error) for plots of the short distance category and $8.96 \pm 0.78 \mathrm{~m}$ for plots of the long distance category without significant differences between the vegetation types (Kruskal-Wallis rank sum test: short, $\chi^{2}=0.39, \mathrm{df}=3, p=0.94$; long, $\chi^{2}=1.09, \mathrm{df}=3, p=$ $0.78)$. It should be noted that the similar distance of the vegetation types to the creek was important for our study design and characteristic of our study area.
All vegetation structure characteristics differed significantly between the vegetation types (Table 3; Fig. 2b-h). The Salicornia and Limonium types were both characterized by low plant biomass, low vegetation height and short, mostly unbranched stems with a small diameter. However, total cover was on average lower for the Salicornia type and varied more, compared to the other vegetation types where total cover was almost $100 \%$. The Spartina type was characterized by high plant biomass, tall vegetation and long, thick and mostly unbranched stems. The Atriplex type also had high plant biomass, but a lower vegetation height and long, highly branched stems with an intermediate stem diameter. The high mean and large variation in stem density for the Salicornia and Spartina types was caused by some plots with extreme stem densities due to a large number of $P$. maritima.

\section{Sedimentation}

Vegetation presence (LMM: $\mathrm{df}=55, \mathrm{~F}=16.63, p<0.001$ ), vegetation type (LMM: $\mathrm{df}=18, \mathrm{~F}=9.50, p<0.001)$ and distance to the creek (LMM: $\mathrm{df}=27, \mathrm{~F}=11.52, p=0.002$ ) all had a significant effect on sedimentation (marginal $\mathrm{R}^{2}=$ 0.346 , conditional $\mathrm{R}^{2}=0.905$; note that sedimentation was always $\log$ transformed) (Fig. 3). Sedimentation was on average $42 \%$ higher in the presence of vegetation compared to locations where vegetation was removed. This positive effect of vegetation on sedimentation did not significantly differ between vegetation types or between distances to the creek, as illustrated by the absence of significant interaction effects. No obvious signs of erosion of the soil surface were observed in the subplots where vegetation was removed. Only the Limonium type was significantly different from the other vegetation types. Sedimentation was on average more than five times higher for the Atriplex and Spartina types and more than eleven times higher for the Salicornia type compared to the Limonium type. On average $60 \%$ more sedimentation took place in plots at a short distance to the creek compared to

Table 3 Chi-squared, degrees of freedom and $p$ values for KruskalWallis rank sum tests to compare seven vegetation characteristics between the vegetation types Salicornia, Spartina, Atriplex and Limonium

\begin{tabular}{llll}
\hline Vegetation characteristic & $\chi^{2}$ & df & $p$ value \\
\hline Total cover & 31.89 & 3 & $<0.001$ \\
Vegetation height & 38.29 & 3 & $<0.001$ \\
Stem height & 26.39 & 3 & $<0.001$ \\
Stem diameter & 32.78 & 3 & $<0.001$ \\
Branching level & 26.80 & 3 & $<0.001$ \\
Stem density & 10.57 & 3 & 0.014 \\
Biomass & 32.23 & 3 & $<0.001$ \\
\hline
\end{tabular}




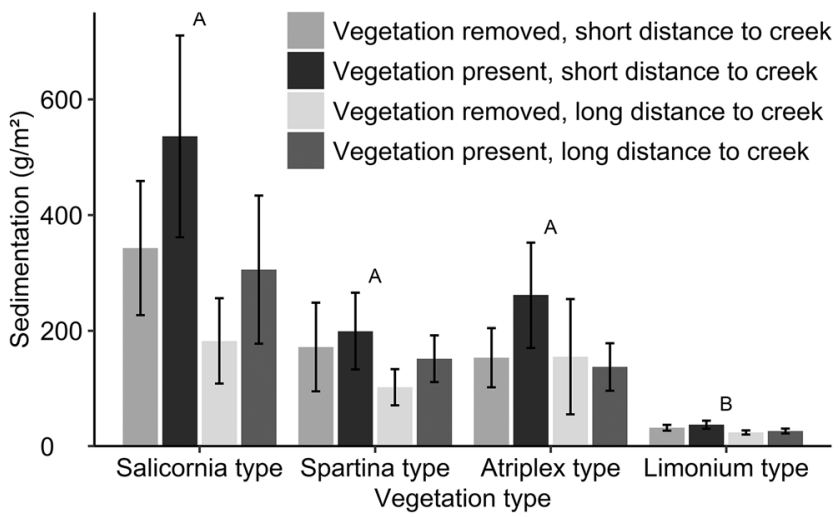

Fig. 3 Means with standard error of sedimentation over a period of two weeks in four vegetation types. In each vegetation type, plots are located at a short or long distance to the creek. In each plot, vegetation is removed in one of the two subplots. The capital letters above the bars of each vegetation type indicate significant groups based on multiple comparisons after a linear mixed model

the long distance category. No interaction effect was found between distance to the creek and vegetation type on sedimentation.

Although sedimentation was mostly correlated with stem diameter and stem density from the vegetation characteristics based on Spearman rank correlations (Table 1), the linear mixed model with branching level was the best from the six models with one vegetation characteristic as the AICc was lowest and the marginal pseudo $\mathrm{R}^{2}$ was highest (Table 4). Stem height (LMM: $\mathrm{df}=47, \mathrm{~F}=3.93, p=0.053$; marginal $\mathrm{R}^{2}=0.320$, conditional $\left.\mathrm{R}^{2}=0.901\right)$ and branching level (LMM: $\mathrm{df}=47, \mathrm{~F}=10.02, p=0.003$; marginal $\mathrm{R}^{2}=0.363$, conditional $\mathrm{R}^{2}=0.901$ ) were significant in the models, while other vegetation characteristics were not significant. Sedimentation increased exponentially with both stem height and branching level (Fig. 4a, b; note the logarithmic scale of the y-axes).

Branching level was also important based on the analysis of the ten models with two vegetation characteristics. In this case, the model with the combination branching level and stem diameter was the best based on the AICc and marginal pseudo $\mathrm{R}^{2}$ (Table 4). The interaction between branching level and stem diameter was significant (LMM: $\mathrm{df}=45, \mathrm{~F}=4.43$, $p=0.041$; marginal $\mathrm{R}^{2}=0.398$, conditional $\left.\mathrm{R}^{2}=0.904\right)$. Branching level significantly affected sedimentation in the final model (LMM: $\mathrm{df}=45, \mathrm{~F}=10.69, p=0.002$ ), while stem diameter was not significant (LMM: $\mathrm{df}=45, \mathrm{~F}=1.08, p=$ $0.30)$. The interaction between stem diameter and branching level suggests that branching level only has a positive effect on sedimentation when the stem is thick enough (above $1.3 \mathrm{~cm}$ ). The AICc of the model with the combination branching level and stem height was similar, but only branching level was significant in this model (LMM: $\mathrm{df}=$ $47, \mathrm{~F}=10.02, p=0.003$; marginal $\mathrm{R}^{2}=0.363$, conditional $\left.\mathrm{R}^{2}=0.901\right)$.
Elevation (LMM: $\mathrm{df}=45-47, \mathrm{~F}=37.59-45.28, p<0.001$; df and $F$ depend on the model considered) and vegetation presence (LMM: $\mathrm{df}=55, \mathrm{~F}=16.63, p<0.001$ ) were always significant in the models with one or two vegetation characteristics. Sedimentation decreased exponentially with elevation (Fig. 4c; note the logarithmic scale of the y-axes) and was positively affected by vegetation presence as before (Fig. 4). Interactions between vegetation presence and vegetation characteristics were never significant, suggesting that stem height and branching level of the surrounding vegetation still affected sedimentation in the subplots where vegetation was removed.

\section{Sediment Grain Size}

A significant effect was found of vegetation type on median grain size (LMM: $\mathrm{df}=18, \mathrm{~F}=4.87, p=0.012$ ), while distance to the creek or an interaction was not significant (marginal $\mathrm{R}^{2}=0.320$; conditional $\mathrm{R}^{2}=0.859$; note that median grain size was always log transformed) (Fig. 5). Median grain size was on average more than two times higher for the Atriplex and Spartina types and almost seven times higher for the Salicornia type compared to the Limonium type. However, only the median grain size of the Salicornia type was significantly different from the other vegetation types. This higher grain size for the Salicornia type was reflected in a high sand percentage of on average $58 \%$ compared to $18-27 \%$ for the other vegetation types.

The effect of vegetation characteristics on median grain was studied only for plots with a low median grain size. Total cover and branching level had the highest Spearman rank correlation coefficients with median grain size from the seven vegetation characteristics (Table 1). The model with branching level also had the lowest AICc and highest marginal pseudo $\mathrm{R}^{2}$, compared to the other models for median grain size with one vegetation characteristic (Table 4). However, none of the vegetation characteristics were significant. From the sixteen mixed models with two vegetation characteristics, the model with the combination branching level and stem diameter was the best model based on their AICc and marginal pseudo $\mathrm{R}^{2}$ (Table 4 ). The models with the combinations biomass and branching level or vegetation height and branching level were similar (AICc difference $<2$ ). However, the vegetation characteristics or interactions were not significant. Branching level and distance to the creek (m) were both just not significant $(0.1>p>0.05)$ in the models for median grain size, but a positive and negative exponential trend can be observed, respectively (Fig. S2, Online Resource; note the logarithmic scale of the y-axes). Very little variance is explained in the models for median grain size with vegetation characteristics as the marginal and conditional pseudo $\mathrm{R}^{2}$ were very low (Table 4). 
Table 4 Second-order Akaike Information Criterion (AICc) and marginal (m) and conditional (c) pseudo $\mathrm{R}^{2}$ of several linear mixed models for sedimentation or median grain size with one or two vegetation characteristics. Note that sedimentation, median grain size and stem density were always $\log$ transformed and that backward model simplification is not yet applied. Lowest or similar AICc (difference $<2$ ) and highest marginal pseudo $\mathrm{R}^{2}$ are indicated in bold

\begin{tabular}{|c|c|c|c|c|c|c|}
\hline \multirow[t]{2}{*}{ Vegetation characteristics } & \multicolumn{3}{|c|}{ Sedimentation } & \multicolumn{3}{|c|}{ Median grain size } \\
\hline & $\mathrm{AICc}$ & $\mathrm{R}^{2}(\mathrm{~m})$ & $\mathrm{R}^{2}(\mathrm{c})$ & $\mathrm{AICc}$ & $\mathrm{R}^{2}(\mathrm{~m})$ & $\mathrm{R}^{2}(\mathrm{c})$ \\
\hline- & - & 0.296 & 0.900 & - & 0.083 & 0.083 \\
\hline Total cover & - & - & - & -52.8 & 0.089 & 0.089 \\
\hline Vegetation height & 67.1 & 0.305 & 0.900 & -52.9 & 0.093 & 0.093 \\
\hline Stem height & 61.9 & 0.343 & 0.900 & -52.5 & 0.083 & 0.083 \\
\hline Stem diameter & 64.4 & 0.326 & 0.899 & -52.6 & 0.085 & 0.085 \\
\hline Branching level & $\mathbf{5 8 . 7}$ & 0.384 & 0.897 & -56.0 & 0.158 & 0.158 \\
\hline Stem density & 66.1 & 0.320 & 0.897 & -53.6 & 0.108 & 0.108 \\
\hline Biomass & 65.7 & 0.324 & 0.899 & -52.5 & 0.084 & 0.084 \\
\hline Total cover*vegetation height & - & - & - & -47.9 & 0.106 & 0.106 \\
\hline Total cover*stem height & - & - & - & -47.3 & 0.093 & 0.093 \\
\hline Total cover*stem diameter & - & - & - & -47.5 & 0.098 & 0.098 \\
\hline Total cover*branching level & - & - & - & -51.4 & 0.179 & 0.179 \\
\hline Total cover*stem density & - & - & - & -48.4 & 0.115 & 0.115 \\
\hline Total cover*biomass & - & - & - & -49.4 & 0.138 & 0.138 \\
\hline Vegetation height*branching level & 64.1 & 0.417 & 0.898 & -53.3 & 0.216 & 0.216 \\
\hline Vegetation height*stem density & 72.1 & 0.355 & 0.895 & -48.7 & 0.122 & 0.122 \\
\hline Stem height*branching level & 63.0 & 0.407 & 0.903 & -51.2 & 0.175 & 0.175 \\
\hline Stem height*stem density & 64.8 & 0.394 & 0.903 & -48.4 & 0.117 & 0.117 \\
\hline Stem diameter*branching level & 61.1 & 0.428 & 0.902 & $-\mathbf{5 3 . 9}$ & 0.226 & 0.226 \\
\hline Stem diameter*stem density & 69.2 & 0.344 & 0.903 & -48.9 & 0.127 & 0.127 \\
\hline Stem diameter*biomass & 68.9 & 0.335 & 0.908 & -47.1 & 0.088 & 0.088 \\
\hline Branching level*stem density & 67.3 & 0.385 & 0.899 & -50.6 & 0.162 & 0.162 \\
\hline Branching level*biomass & 64.7 & 0.394 & 0.903 & -53.7 & 0.223 & 0.223 \\
\hline Stem density*biomass & 72.2 & 0.353 & 0.898 & -48.5 & 0.120 & 0.120 \\
\hline
\end{tabular}

\section{Modelled Wave Attenuation}

The significant wave height that was modelled with XBeach along a transect in the Slufter increased on the beach and then slowly declined when vegetation was absent or declined exponentially when vegetation was present until the dike was reached (Fig. 6; Table 2). The modelled total wave attenuation over the salt marsh was clearly higher for the scenario with zonation of the vegetation types (wave attenuation of 98\%) compared to the scenario where vegetation is absent (13\%). Differences between the vegetation types were most pronounced for the first $100 \mathrm{~m}$ of salt-marsh vegetation. The Salicornia type with the shortest stems had the weakest modelled wave attenuation (29\%). Wave attenuation was higher for the Atriplex type (45\%), which had taller and thicker stems with a similar density, and for the Limonium type (57\%), which had similar stem heights and stem diameters as the Salicornia type but twice the stem density. Wave attenuation was strongest for the Spartina type (72\%), which had the tallest and thickest stems.

The sensitivity analysis of vegetation characteristics based on field measurements indicated that modelled wave attenuation was most sensitive to the natural variance in stem density (Fig. 7; Table 2). As expected, stem height, stem diameter and stem density all positively influenced wave attenuation in the XBeach model. The maximum scenarios for the stem height, stem diameter and stem density resulted in equally more wave attenuation (78-81\% wave attenuation for the first $100 \mathrm{~m}$ ) compared to the average scenario $(57 \%)$. The minimum scenarios resulted in an equally weaker wave attenuation for stem height and stem diameter (29 and 32\%), but to a very strong reduction in the wave attenuation capacity for stem density (1.6\%). The total wave attenuation over the saltmarsh vegetation was still low for the minimum stem density scenario (66\%) compared to the other scenarios (95-99\%).

\section{Discussion}

\section{Vegetation Presence}

The presence of vegetation increased sedimentation on average by $42 \%$ relative to small-scale vegetation removal in our study area, illustrating the importance of vegetation presence 
$\sim$ Vegetation removed

Vegetation present
- Salicornia type

- Spartina type

- Atriplex type

- Limonium type
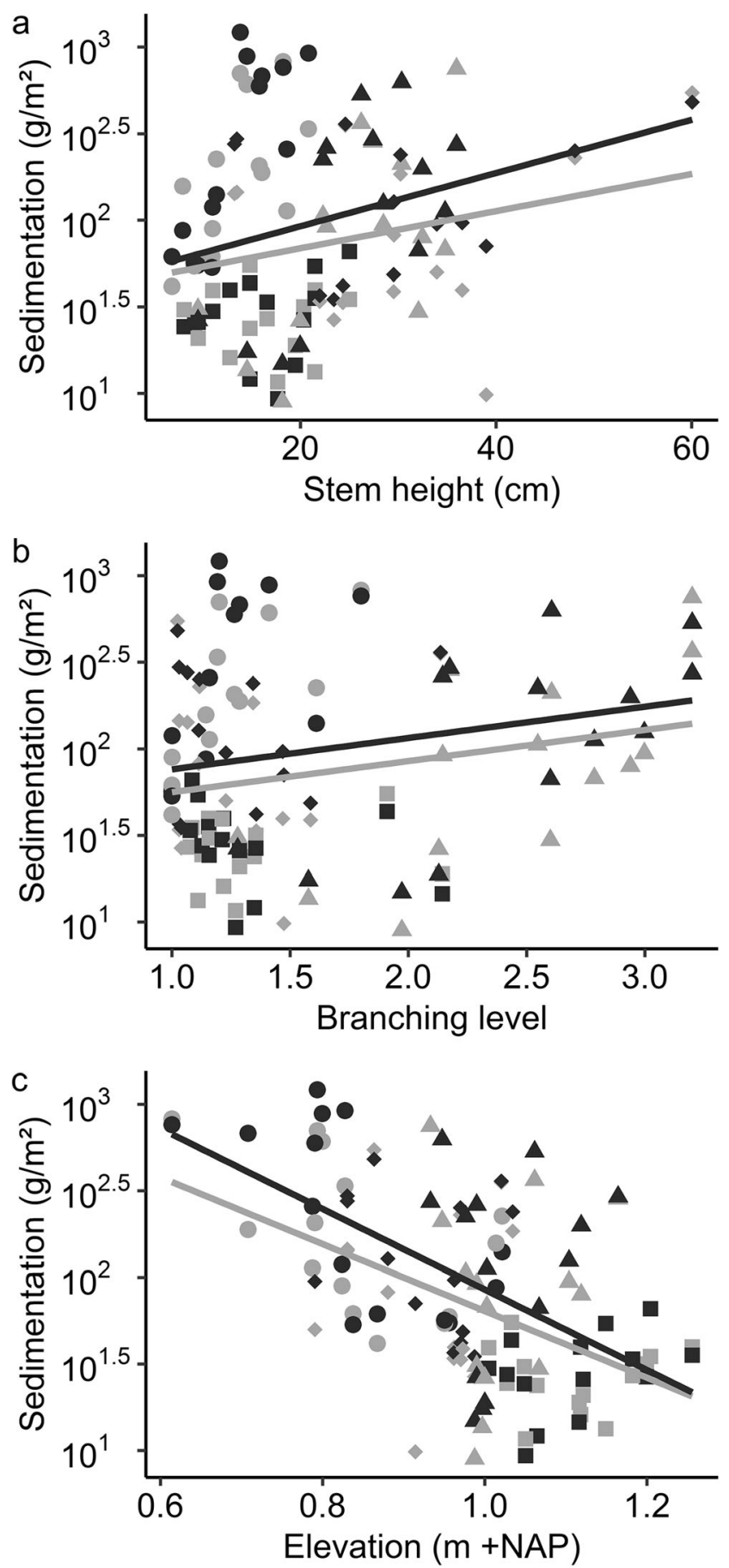

Fig. 4 The vegetation characteristics a stem height and $\mathbf{b}$ branching level significantly influenced sedimentation in two separate linear mixed models, together with vegetation presence and c elevation. Measurements are indicated per vegetation type, although the effect of vegetation type on sedimentation is tested in another model. Note that the $\mathrm{y}$-axes have a logarithmic scale for the adaptive capacity of salt marshes to sea level rise. Due to our study design, we were able to rule out geomorphological effects such as elevation and distance to the source of sediment. Although we were not able to fully exclude that plant material from the surrounding vegetation in subplots where vegetation was present contributed to the dry weight in the sediment traps, we expect this to have a limited contribution to the vegetation effect. Our results are consistent with Culberson et al. (2004), who measured on average almost two times more sedimentation in vegetated locations compared to unvegetated locations of $1 \mathrm{~m}^{2}$ in two estuarine marshes. Field and modelling studies showed that large-scale vegetation removal can result in spatially redistributed sedimentation (Temmerman et al. 2005; Schepers et al. 2020), sheet flow and increased flow velocities over the marsh platform (Temmerman et al. 2005; Temmerman et al. 2012; Schepers et al. 2020). Whether the reduction in sediment deposition we observed after small-scale removal of marsh vegetation is due to a locally enhanced water flow velocity needs further study. Our results confirm the major contribution of salt-marsh vegetation to sedimentation, which is important for the vertical growth of salt marshes to keep up with sea level rise. This importance of vegetation is also illustrated by studies that found decreased accretion rates, erosion and loss of elevation after vegetation dieback (Baustian et al. 2012; Coleman and Kirwan 2019).

We investigated the vegetation effect on sedimentation in four vegetation types. No statistically significant interaction was found between vegetation presence and vegetation type on sedimentation. However, the presence of vegetation increased sedimentation on average by 14, 29, 28 and $60 \%$ relative to vegetation removal for the vegetation types Limonium, Atriplex, Spartina and Salicornia respectively. This suggests the strongest impact for vegetation types where elevation is low and sediment availability is high, stressing the importance of the pioneer Salicornia species as key initiators

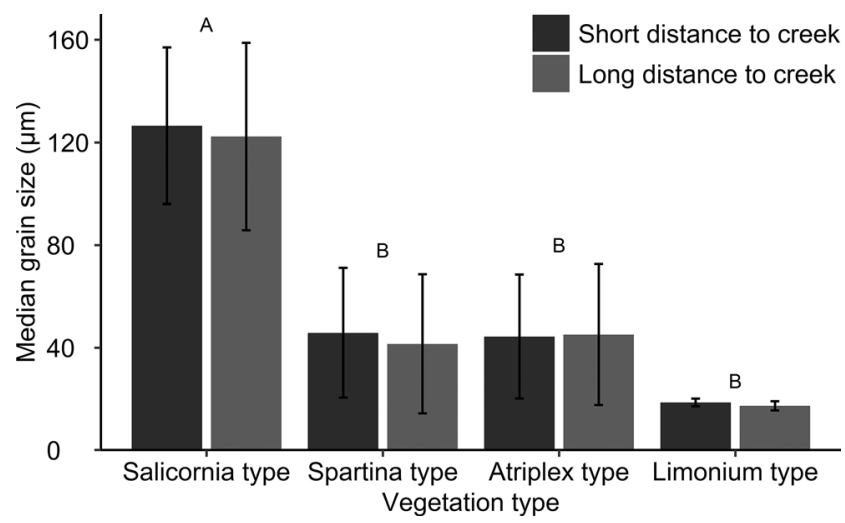

Fig. 5 Means with standard error of median grain size of the sediment in four vegetation types. In each vegetation type, plots are located at a short or long distance to the creek. The capital letters above the bars of each vegetation type indicate significant groups based on multiple comparisons after a linear mixed model 
of the biophysical feedback between salt-marsh vegetation and sedimentation.

The wave attenuation of $98 \%$ modelled in XBeach over the $2.5 \mathrm{~km}$ transect representing the salt marsh in the Slufter suggests that the significant wave height is almost zero in front of the sand dike under modelling conditions. This is mostly attributed to the presence of vegetation, not topography, in our study area, as modelled wave attenuation was only $13 \%$ when vegetation was absent. Our modelled wave attenuation $(76 \%$ over the first $180 \mathrm{~m}$ ) is in line with the measured wave attenuation by Möller et al. (1999) for low marsh vegetation with a similar species composition (on average $61 \%$ for a $180 \mathrm{~m}$ transect). Wave attenuation over the salt marsh was around $50 \%$ higher than over a bare sand flat seaward of the salt marsh for similar water depths (Möller et al. 1999). While our 1D approach is sufficient to explore potential wave attenuation by vegetation, a 2D model that also includes processes like diffraction or wave-current interactions will give more accurate predictions of the wave height in the Slufter. Given that we modelled the peak of the storm at high tide (when tidal currents are minimal) and did not include wave diffraction, wave heights can be expected to reduce further in a 2D approach. The exponential decrease of modelled wave height over vegetated salt marshes we observed is also found by field studies (Möller et al. 1999; Yang et al. 2012) and indicates that wave height is mainly reduced in the first part of the salt marsh. This suggests that proper management of the most

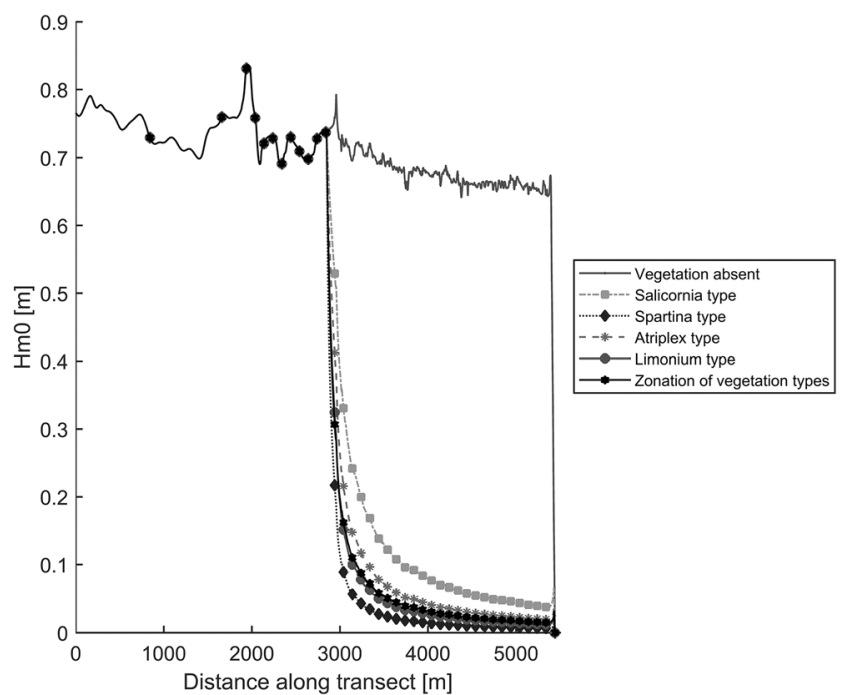

Fig. 6 Significant wave height $(\mathrm{Hm} 0)$ along the transect $(5.4 \mathrm{~km})$ modelled with XBeach for six vegetation scenarios and for a water level of $2.8 \mathrm{~m}+\mathrm{NAP}$, a wave height of $0.9 \mathrm{~m}$ and a wave period of $5 \mathrm{~s}$. The vegetation scenarios are based on field measurements of vegetation characteristics. The first scenario (vegetation absent) served as a reference. One of the four vegetation types is present in the next four scenarios (Salicornia type, Spartina type, Atriplex type, Limonium type). The last scenario (zonation of the four vegetation types) represents the field situation. The salt-marsh vegetation occurs in the last $2.5 \mathrm{~km}$ of the transect seaward part of a salt marsh is important with respect to flood protection.

\section{Vegetation Type}

Sedimentation was highest in the Salicornia type, intermediate for the Spartina and Atriplex types and lowest for the Limonium type. The same pattern was observed for sediment grain size. Sedimentation differences between vegetation types were also observed by Silva et al. (2009) in Portugal and by French and Spencer (1993) in the UK as a result of differences in distance to the creek (French and Spencer 1993; Silva et al. 2009) and elevation (French and Spencer 1993). Yang (1999a) and Yang et al. (2008) observed larger grain sizes for low marsh vegetation compared to high marsh vegetation in the Yangtze River Delta, China. This is likely due to a landward decrease of the flow velocity and wave energy (Yang 199a; Yang et al. 2008). The vegetation types in our study area were similar in their distance to the creek, controlling for the distance to the sediment source, but did differ in elevation and vegetation characteristics. As sedimentation and grain size is generally found to decrease with elevation (e.g., Yang 1999b; Yang et al. 2008; Townend et al. 2011; Reef et al. 2018), sedimentation and grain size differences between the vegetation types in our study are most likely explained by a combination of elevation and vegetation characteristics. Our results confirm that large sediment particles are rapidly deposited in the Salicornia vegetation as water enters the salt marsh and thus this pioneer vegetation will enhance accretion more than in the higher marsh.

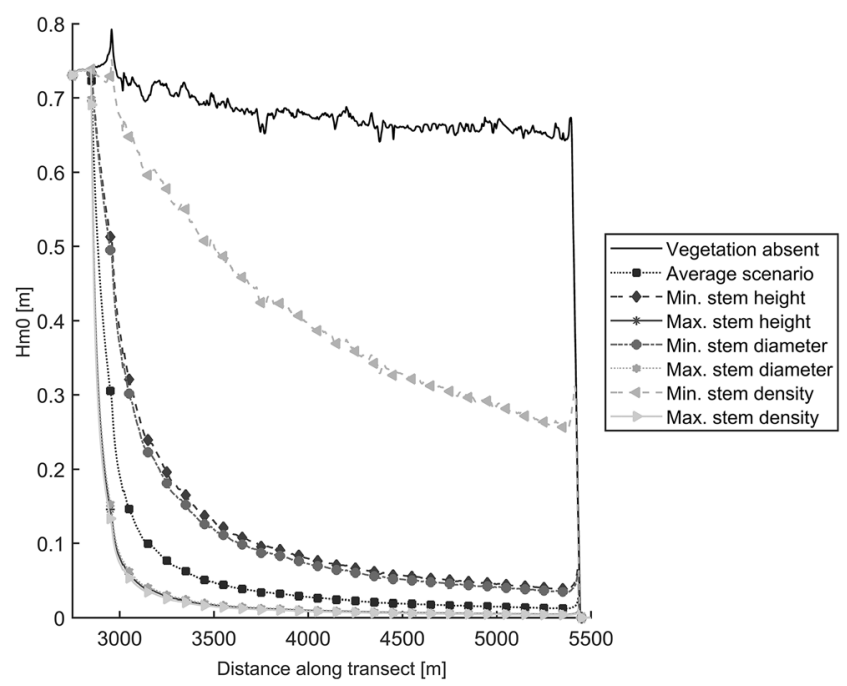

Fig. 7 Significant wave height $(\mathrm{Hm} 0)$ along the transect $(5.4 \mathrm{~km})$ modelled with XBeach for seven sensitivity scenarios and for a water level of $2.8 \mathrm{~m}+\mathrm{NAP}$, a wave height of $0.9 \mathrm{~m}$ and a wave period of $5 \mathrm{~s}$. The sensitivity scenarios for three vegetation characteristics are based on field measurements. Only the last $2.5 \mathrm{~km}$ of the transect is shown, where salt-marsh vegetation occurs. The scenario where vegetation is absent is shown for comparison. Note that the significant wave height of the three maximum scenarios is overlapping 
Modelled wave attenuation was strongest for the Spartina type (72\% for the first $100 \mathrm{~m}$ ) and weakest for the Salicornia type $(29 \%)$. In contrast to sedimentation, the differences in modelled wave attenuation between the vegetation types can only be attributed to differences in values for the height, diameter and density of the stems, as the elevation profile and drag coefficient were the same in all scenarios. Stems of the Spartina type were more than two times taller and thicker than the stems of the Salicornia type. In the field, however, water depth and incoming wave height can differ between vegetation types and will reduce or increase wave attenuation, respectively (e.g., Möller et al. 1999; Möller 2006; Maza et al. 2015; Vuik et al. 2016). For simplicity, the drag coefficient was the same in all scenarios, although it is likely to vary between vegetation types as vegetation characteristics can influence the drag coefficient (Nepf 2011). More flexible vegetation, for example, can have a lower drag coefficient than rigid vegetation (van Veelen et al. 2020). The stems of the dominating species in the vegetation types we studied are relatively stiff, although some other species are more flexible like Puccinellia maritima and Suaeda maritima (Bouma et al. 2013; Möller et al. 1999). Vuik et al. (2016) observed more wave attenuation by a Scirpus maritimus marsh compared to a $S$. anglica marsh for the same wave height and water depth, likely due to a higher biomass density of the $S$. maritimus marsh. We found that modelled wave attenuation was stronger for the scenario with a zonation of the four vegetation types (60\% for the first $100 \mathrm{~m}$ ) compared to the average wave damping of the individual vegetation types weighted to their occurrence $(51 \%)$, indicating the importance of including vegetation zonation in the model. Field measurements of wave attenuation in various vegetation types are required to validate our modelling results.

\section{Vegetation Characteristics}

While positive effects of biomass (field experiment, Morris et al. 2002) and stem density (laboratory experiment, Gleason et al. 1979) on sedimentation are reported for Spartina alterniflora, we found that especially stem height and branching level positively affected sedimentation in our study area. Our study is distinguished by the relatively large number of vegetation characteristics and species considered in the field. No effects of vegetation height and biomass were observed for Spartina alterniflora in a field flume experiment during calm summer conditions by sequential removal of plant material (Reef et al. 2018). These results suggest that effects of vegetation characteristics can depend on the season, the species and on the importance of vegetation relative to geomorphological and hydrodynamic factors (e.g., Davidson-Arnott et al. 2002; Wood and Hine 2007; Townend et al. 2011). Based on our study, tall (e.g., Spartina species) and highly branched (e.g.,
A. portulacoides) salt marsh vegetation will best enhance sedimentation. However, it should be noted that the elevation range where species grow determine sedimentation as well. We encourage to further investigate the role of vegetation characteristics in sedimentation for multiple sites, species, seasons and weather conditions and for a longer period. Artificial manipulation of vegetation characteristics could be investigated with the method used by Reef et al. (2018) with treatments at locations subjected to the same geomorphological effects (e.g., elevation, distance to the sea) as in our experiment for vegetation presence.

Although we observed a positive effect of branching level on median grain size for plots with a low grain size, we found no significant effects of vegetation characteristics on sediment grain size. Gibeault et al. (2016) also found no significant effects of vegetation height and cover on grain size in a subarctic salt marsh. However, Yang (1999a) observed that sediment was usually finer in denser and higher marsh vegetation in the Yangtze Delta, China. A negative relation was found between grain size and the product of plant height and cover (Yang et al. 2008). Possibly, hydrodynamic factors were more dominant in our study system, resulting in plots with either a large or small median grain size. An alternative explanation could be that current vegetation characteristics are not representative for the period of sedimentation that is represented by the top $1 \mathrm{~cm}$ of the sampled soil used for measuring the grain size distribution.

Unsurprisingly, an increase in stem height, stem diameter and stem density all increased modelled wave attenuation. These results are consistent with flume experiments, which showed positive effects on wave attenuation by the stem height to water depth ratio and stem density (e.g., Augustin et al. 2009; Bouma et al. 2010; Anderson and Smith 2014; Peruzzo et al. 2018). Based on a sensitivity analysis using field measurements of stem height, stem diameter and stem density, modelled wave attenuation in our study was most sensitive to the natural variation in stem density, dropping strongly for the minimum stem density of $96 \mathrm{stems} / \mathrm{m}^{2}$. The relative importance of stem density is also indicated by other modelling studies (van Loon-Steensma et al. 2014; Kalra et al. 2017; Garzon et al. 2019b). This suggests that salt marshes with low density vegetation are less suited for flood protection by attenuating waves, which is relevant to consider for constructing or restoring salt marshes. Besides, our results imply that maximizing vegetation characteristics like the density could increase wave attenuation. However, field experiments testing the relative importance of vegetation characteristics on wave attenuation are required to validate our modelling results.

Vegetation characteristics, such as stem height, diameter and density, can decrease during winter, potentially reducing the positive vegetation effect on sedimentation and wave attenuation (Silinski et al. 2016; Garzon et al. 2019b). This reduction will likely be larger for the Salicornia type relative 
to the Spartina, Atriplex and Limonium types, because annual Salicornia species can completely disappear during winter (Bouma et al. 2014), while the perennial plants S. anglica, $A$. portulacoides and $L$. vulgare will only lose part of their biomass. As a result, the capacity of the salt marsh to aid in flood protection can be severely reduced depending on the plant species present.

\section{Implications for Salt-Marsh Functioning and Future Challenges}

Our results underscore the importance of plant species composition in salt marshes for sedimentation and expected wave attenuation. Therefore, the composition of the salt marsh vegetation is crucial to understand the biophysical feedbacks between inundation, plant growth and sediment deposition and predict the marsh's response to sea level rise (Kirwan et al. 2016). Because of the natural adaptive capacity of salt marshes and potential wave attenuation by vegetation, salt marshes can be considered in nature-based solutions for coastal protection (Temmerman et al. 2013; Vuik et al. 2016). Our study indicates that these services are influenced by vegetation type and vegetation characteristics. We found that sedimentation increased with stem height and branching level. Our model exploration suggests that natural variation in vegetation characteristics, especially stem density, has a significant influence on modelled wave attenuation rates. This implies that changes in vegetation characteristics and species composition in the future, due to for example climate change and invasive species, can affect salt-marsh functioning (e.g., Wang et al. 2006; Kirwan et al. 2009; Ysebaert et al. 2011; Watson et al. 2014; Ratliff et al. 2015). Although further field research is required to gain more insights in the relative importance of vegetation characteristics to geomorphological and hydrodynamic factors, management can be adapted to this by stimulating plant growth or promoting specific species to maximize vegetation characteristics. Furthermore, our results suggest that model predictions of salt-marsh accretion and wave attenuation can be improved by incorporating differences in vegetation characteristics between vegetation types.

\section{Conclusion}

The purpose of this study was to investigate the role of saltmarsh vegetation in sedimentation, sediment grain size and modelled wave attenuation in the Slufter, the Netherlands, with an outlook for implementing the natural adaptive capacity of salt marshes to sea level rise in nature-based flood defences. Vegetation presence increased sedimentation on average by $42 \%$ and positively affected modelled wave attenuation, which is consistent with the results of a meta-analysis by Shepard et al. (2011). Sedimentation, sediment grain size and modelled wave attenuation were all different for the four vegetation types. Stem height and branching level were found to affect sedimentation, while a non-significant effect of branching level was found on sediment grain size. Modelled wave attenuation was affected most by the natural variability in stem density. Our results suggest that the natural adaptive capacity and flood protection role of salt marshes are affected by the type and characteristics of the vegetation and thereby also by vegetation management.

\section{Appendix: Implementation of vegetation in the XBeach model}

In the surf-beat mode used for this study, XBeach propagates waves within the 1D domain following the wave action balance (Roelvink et al. 2009; van Rooijen et al. 2016):

$\frac{\partial A}{\partial t}+\frac{\partial c_{x} A}{\partial x}+\frac{\partial c_{\theta} A}{\partial \theta}=\frac{\sum D}{\sigma}$,

where: $A=$ Wave $\operatorname{action} \frac{J}{m}$,

$c=$ Wave celerity $\frac{m}{s}$,

$\theta=$ Wave direction $\mathrm{rad}$,

$D=$ Wave energy dissipation $\frac{J}{m s^{2}}$,

$\sigma=$ Intrinsic frequency $\frac{1}{s}$.

In XBeach, dissipation by a layer of vegetation is modelled with the approach by Suzuki et al. (2012) based on the formulation by Mendez and Losada (2004):

$D_{v, i}=A_{v} * \frac{\rho \widetilde{C}_{D, i} b_{v, i} N_{v, i}}{2 \sqrt{\pi}}\left(\frac{k g}{2 \sigma}\right)^{3} H_{r m s}{ }^{3}$,

with $A_{v}=\frac{\sinh ^{3} k \alpha_{i} h-\sinh ^{3} k \alpha_{i-1} h+3\left(\sinh ^{3} k \alpha_{i} h-\sinh ^{3} k \alpha_{i-1} h\right)}{3 k \cosh ^{3} k h}$,

where: $D_{v}=$ Dissipation by vegetation $\frac{J}{m s^{2}}$,

$\widetilde{C}_{D}=$ Bulk drag coefficient - ,

$b_{v}=$ The vegetation stem diameter $m$,

$N_{v}=$ Vegetation density $\frac{\mathrm{stems}}{\mathrm{m}^{2}}$,

$\alpha=$ Factor of vegetation height $\left(h_{v}\right)$ as: $h_{v} / h-$,

and: $\rho=$ Water density $\frac{\mathrm{kg}}{\mathrm{m}^{3}}$,

$H_{r m s}=$ Root mean square wave height $m$,

$k=$ Wave number $\frac{1}{m}$,

$h=$ Water depth $m$.

Vegetation in XBeach is modelled as an energy sink for waves. The magnitude of the energy loss is calculated with the vegetation characteristics like stem diameter, density, and height. Results are calibrated with the bulk drag coefficient to account for attributes not included in the model like the shape and deformation of the stems during wave loads.

The XBeach model can adequately predict wave attenuation after calibration of the bulk drag coefficient (van Rooijen 
et al. 2016; Garzon et al. 2019a, 2019b). The formulation by Mendez and Losada (2004) is also implemented in the SWAN model by Suzuki et al. (2012) and several studies (e.g., Vuik et al. 2016; Baron-Hyppolite et al. 2019) have demonstrated that after calibration this extended SWAN model can adequately predict wave attenuation across a salt marsh.

Supplementary Information The online version contains supplementary material available at https://doi.org/10.1007/s13157-021-01467-w.

Acknowledgements We are indebted to the Dutch State Forest Service, and more specifically Erik van der Spek, for allowing access to the salt marsh of nature reserve the Slufter (Dutch Wadden island of Texel). Facilities for the grain size distribution analysis were provided by the Vrije Universiteit Amsterdam. We thank dr. Maarten Prins and Martina Hagen of the Sediment Laboratory for help during the grain size distribution analysis and thank Petra Goessen of Water Board Hoogheemraadschap Hollands Noorderkwartier for facilitating this research. Furthermore, we would like to thank the anonymous reviewers for their helpful comments to improve our paper.

Availability of Data and Material The dataset on plant characteristics and sedimentation generated during and/or analysed during the current study is available at https://doi.org/10.5281/zenodo.4312767.

Authors' Contributions JVLS and JL conceived ideas. BB designed the field experiment and performed the field work, lab work and data analysis. JK performed the modelling work. JvLS, JL and RM supervised the project. BB wrote the article with support from JvLS, JL, RM and JK.

Funding Water Board Hoogheemraadschap Hollands Noorderkwartier provided funding for the grain size distribution analysis at the Vrije Universiteit Amsterdam.

\section{Declarations}

Conflicts of Interest/Competing Interests Authors declare that they have no conflict of interest.

Ethics Approval The responsible nature management organization gave consent for our field experiments.

Consent to Participate Not applicable.

Consent for Publication Not applicable.

Code Availability XBeach is a public domain model (https://oss. deltares.n1/web/xbeach/) and SynBioSys is a public domain information system (https://www.synbiosys.alterra.nl/).

\section{References}

Adam P (2002) Saltmarshes in a time of change. Environmental Conservation 29:39-61

Anderson ME, Smith JM (2014) Wave attenuation by flexible, idealized salt marsh vegetation. Coastal Engineering 83:82-92

Augustin LN, Irish JL, Lynett P (2009) Laboratory and numerical studies of wave damping by emergent and near-emergent wetland vegetation. Coastal Engineering 56:332-340
Barbier EB, Hacker SD, Kennedy C, Koch EW, Stier AC, Silliman BR (2011) The value of estuarine and coastal ecosystem services. Ecological Monographs 81:169-193

Baron-Hyppolite C, Lashley CH, Garzon J, Miesse T, Ferreira C, Bricker JD (2019) Comparison of implicit and explicit vegetation representations in SWAN hindcasting wave dissipation by coastal wetlands in Chesapeake Bay. Geosciences 9:8

Barton K (2018) MuMIn: Multi-model inference. R package version 1.42.1. https://CRAN.R-project.org/package=MuMIn

Baustian JJ, Mendelssohn IA, Hester MW (2012) Vegetation's importance in regulating surface elevation in a coastal salt marsh facing elevated rates of sea level rise. Global Change Biology 18:33773382

Bouma TJ, de Vries MB, Herman PMJ (2010) Comparing ecosystem engineering efficiency of two plant species with contrasting growth strategies. Ecological Studies 91:2696-2704

Bouma TJ, Temmerman S, van Duren LA, Martini E, Vandenbruwaene W, Callaghan DP, Balke T, Biermans G, Klaassen PC, van Steeg P, Dekker F, van de Koppel J, de Vries MB, Herman PMJ (2013) Organism traits determine the strength of scale-dependent bio-geomorphic feedbacks: a flume study on three intertidal plant species. Geomorphology 180-181:57-65

Bouma TJ, van Belzen J, Balke T, Zhu Z, Airoldi L, Blight AJ, Davies AJ, Galvan C, Hawkins SJ, Hoggart SPG, Lara JL, Losada IJ, Maza M, Ondiviela B, Skov MW, Strain EM, Thompson RC, Yang S, Zanuttigh B, Zhang L, Herman PMJ (2014) Identifying knowledge gaps hampering application of intertidal habitats in coastal protection: opportunities \& steps to take. Coastal Engineering 87:147-157

Christiansen T, Wiberg PL, Milligan TG (2000) Flow and sediment transport on a tidal salt marsh. Estuarine, Coastal and Shelf Science 50: 315-331

Coleman DJ, Kirwan ML (2019) The effect of a small vegetation dieback event on salt marsh sediment transport. Earth Surface Processes and Landforms 44:944-952

Crosby SC, Sax DF, Palmer ME, Booth HS, Deegan LA, Bertness MD, Leslie HM (2016) Salt marsh persistence is threatened by predicted sea-level rise. Estuarine, Coastal and Shelf Science 181:93-99

Culberson SD, Foin TC, Collins JN (2004) The role of sedimentation in estuarine marsh development within the San Francisco estuary, California, USA. Journal of Coastal Research 20:970-979

Davidson-Arnott RGD, van Proosdij D, Ollerhead J, Schostak L (2002) Hydrodynamics and sedimentation in salt marshes: examples from a macrotidal marsh, bay of Fundy. Geomorphology 48:209-231

Defina A, Bixio AC (2005) Mean flow and turbulence in vegetated open channel flow. Water Resources Research 41:W07006

French JR, Spencer T (1993) Dynamics of sedimentation in a tidedominated backbarrier salt marsh, Norfolk, UK. Marine Geology 110:315-331

Garzon JL, Maza M, Ferreira CM, Lara JL, Losada IJ (2019a) Wave attenuation by Spartina saltmarshes in the Chesapeake Bay under storm surge conditions. Journal of Geophysical Research, Oceans 124:5220-5243

Garzon JL, Miesse T, Ferreira CM (2019b) Field-based numerical model investigation of wave propagation across marshes in the Chesapeake Bay under storm conditions. Coastal Engineering 146:32-46

Gedan KB, Silliman BR, Bertness MD (2009) Centuries of human-driven change in salt marsh ecosystems. Annual Review of Marine Science $1: 117-141$

Gibeault C, Neumeier U, Bernatchez P (2016) Spatial and temporal sediment dynamics in a subarctic salt marsh (gulf of St. Lawrence, Canada). Journal of Coastal Research 32:1344-1361

Giraudoux P (2018) Pgirmess: spatial analysis and data mining for field ecologists. R package version 1.6.9. https://CRAN.R-project.org/ package $=$ pgirmess 
Gleason ML, Elmer DA, Pien NC, Fisher JS (1979) Effects of stem density upon sediment retention by salt marsh cord grass, Spartina alterniflora Loisel. Estuaries 2:271-273

Hennekens SM, Smits JHJ, Schaminée JHJ (2018) SynBioSys Nederland. Alterra, Wageningen UR

Hothorn T, Bretz F, Westfall P (2008) Simultaneous inference in general parametric models. Biometrical Journal 50:346-363

Kalra TS, Aretxabaleta A, Seshadri P, Ganju NK, Beudin A (2017) Sensitivity analysis of a coupled hydrodynamic-vegetation model using the effectively subsampled quadratures method (ESQM v5.2). Geoscientific Model Development 10:4511-4523

Kirwan ML, Megonigal JP (2013) Tidal wetland stability in the face of human impacts and sea-level rise. Nature 504:53-60

Kirwan ML, Guntenspergen GR, Morris JT (2009) Latitudinal trends in Spartina alterniflora productivity and the response of coastal marshes to global change. Global Change Biology 15:1982-1989

Kirwan ML, Temmerman S, Skeehan EE, Guntenspergen GR, Fagherazzi S (2016) Overestimation of marsh vulnerability to sea level rise. Nature Climate Change 6:253-260

Konert M, Vandenberghe J (1997) Comparison of laser grain size analysis with pipette and sieve analysis: a solution for the underestimation of the clay fraction. Sedimentology 44:523-535

Lavorel S, Grigulis K, McIntyre S, Williams NSG, Garden D, Dorrough J, Berman S, Quétier F, Thébault A, Bonis A (2008) Assessing functional diversity in the field - methodology matters! Functional Ecology 22:134-147

Leonard LA, Hine AC, Luther ME (1995) Surficial sediment transport and deposition processes in a Juncus roemerianus marsh, westCentral Florida. Journal of Coastal Research 11:322-336

Leonardi N, Carnacina I, Donatelli C, Ganju NK, Plater AJ, Schuerch M, Temmerman S (2018) Dynamic interactions between coastal storms and salt marshes: a review. Geomorphology 301:92-107

Li H, Yang SL (2009) Trapping effect of tidal marsh vegetation on suspended sediment, Yangtze Delta. Journal of Coastal Research 25:915-924

Maza M, Lara JL, Losada IJ, Ondiviela B, Trinogga J, Bouma TJ (2015) Large-scale 3-D experiments of wave and current interaction with real vegetation. Part 2: experimental analysis. Coastal Engineering 106:73-86

Mendez FJ, Losada IJ (2004) An empirical model to estimate the propagation of random breaking and nonbreaking waves over vegetation fields. Coastal Engineering 51:103-118

Möller I (2006) Quantifying saltmarsh vegetation and its effect on wave height dissipation: results from a UK east coast saltmarsh. Estuarine, Coastal and Shelf Science 69:337-351

Möller I, Spencer T, French JR, Leggett DJ, Dixon M (1999) Wave transformation over salt marshes: a field and numerical modelling study from North Norfolk, England. Estuarine, Coastal and Shelf Science 49:411-426

Möller I, Kudella M, Rupprecht F, Spencer T, Paul M, van Wesenbeeck BK, Wolters G, Jensen K, Bouma TJ, Miranda-Lange M, Schimmels S (2014) Wave attenuation over coastal salt marshes under storm surge conditions. Nature Geoscience 7:727-731

Morris JT, Sundareshwar PV, Nietch CT, Kjerfve B, Cahoon DR (2002) Responses of coastal wetlands to rising sea level. Ecology 83:28692877

Nepf HM (2011) Flow over and through biota. In: Wolanski E, McLusky D (eds) Treatise on estuarine and coastal science. Academic, Waltham, Massachusetts, pp 267-288

Nolte S, Koppenaal EC, Esselink P, Dijkema KS, Schuerch M, de Groot AV, Bakker JP, Temmerman S (2013) Measuring sedimentation in tidal marshes: a review on methods and their applicability in biogeomorphological studies. Journal of Coastal Conservation 17: $301-325$
Peruzzo P, De Serio F, Defina A, Mossa M (2018) Wave height attenuation and flow resistance due to emergent or near-emergent vegetation. Water 10:402

Pinheiro J, Bates D, DebRoy S, Sarkar D, R Core Team (2018) Nlme: linear and nonlinear mixed effects models. $\mathrm{R}$ package version $3.1-$ 137. https://CRAN.R-project.org/package $=$ nlme

Ratliff KM, Braswell AE, Marani M (2015) Spatial response of coastal marshes to increased atmospheric $\mathrm{CO} 2$. Proceedings of the National Academy of Sciences of the United States of America 112:15580 15584

Redfield AC (1965) Ontogeny of a salt marsh estuary. Science 147:50-55

Reed DJ (1989) Patterns of sediment deposition in subsiding coastal salt marshes, Terrebonne Bay, Louisiana: the role of winter storms. Estuaries 12:222-227

Reed DJ, de Luca N, Foote AL (1997) Effect of hydrologic management on marsh surface sediment deposition in coastal Louisiana. Estuaries 20:301-311

Reed DJ, Spencer T, Murray AL, French JR, Leonard L (1999) Marsh surface sediment deposition and the role of tidal creeks: implications for created and managed coastal marshes. Journal of Coastal Conservation 5:81-90

Reef R, Schuerch M, Christie EK, Möller I, Spencer T (2018) The effect of vegetation height and biomass on the sediment budget of a European saltmarsh. Estuarine, Coastal and Shelf Science 202: $125-133$

Reitsma JM, de Jong J (2019) Toelichting bij de vegetatiekartering Kwelders Texel 2017: Op basis van false colour-luchtfoto's 1: 5.000. Rijkswaterstaat, Delft

Roelvink JA (1993) Dissipation in random wave groups incident on a beach. Coastal Engineering 19:127-150

Roelvink D, Reniers A, van Dongeren A, van Thiel de Vries J, McCall R, Lescinski J (2009) Modelling storm impacts on beaches, dunes and barrier islands. Coastal Engineering 56:1133-1152

Schepers L, van Braeckel A, Bouma TJ, Temmerman S (2020) How progressive vegetation die-off in a tidal marsh would affect flow and sedimentation patterns: a field demonstration. Limnology and Oceanography 65:401-412

Shepard CC, Crain CM, Beck MW (2011) The protective role of coastal marshes: a systematic review and meta-analysis. PLoS One 6: e27374

Shi BW, Yang SL, Wang YP, Bouma TJ, Zhu Q (2012) Relating accretion and erosion at an exposed tidal wetland to the bottom shear stress of combined current - wave action. Geomorphology 138: 380-389

Silinski A, Fransen E, Bouma TJ, Meire P, Temmerman S (2016) Unravelling the controls of lateral expansion and elevation change of pioneer tidal marshes. Geomorphology 274:106-115

Silva H, Dias JM, Caçador I (2009) Is the salt marsh vegetation a determining factor in the sedimentation processes? Hydrobiologia 621: 33-47

Stocker TF, Qin D, Plattner G-K, Tignor MMB, Allen SK, Boschung J, Nauels A, Xia Y, Bex V, Midgley PM (2013) Climate change 2013: the physical science basis, intergovernmental panel on climate change, working group I contribution to the IPCC fifth assessment report (AR5). Cambridge University Press, New York

Suzuki T, Zijlema M, Burger B, Meijer MC, Narayan S (2012) Wave dissipation by vegetation with layer schematization in SWAN. Coastal Engineering 59:64-71

Temmerman S, Govers G, Wartel S, Meire P (2003) Spatial and temporal factors controlling short-term sedimentation in a salt and freshwater tidal marsh, Scheldt estuary, Belgium, SW Netherlands. Earth Surface Processes and Landforms 28:739-755

Temmerman S, Bouma TJ, Govers G, Wang ZB, de Vries MB, Herman PMJ (2005) Impact of vegetation on flow routing and sedimentation patterns: three-dimensional modeling for a tidal marsh. Journal of Geophysical Research - Earth Surface 110:F04019 
Temmerman S, Moonen P, Schoelynck J, Govers G, Bouma TJ (2012) Impact of vegetation die-off on spatial flow patterns over a tidal marsh. Geophysical Research Letters 39:L03406

Temmerman S, Meire P, Bouma TJ, Herman PMJ, Ysebaert T, de Vriend HJ (2013) Ecosystem-based coastal defence in the face of global change. Nature 504:79-83

Torio DD, Chmura GL (2013) Assessing coastal squeeze of tidal wetlands. Journal of Coastal Conservation 29:1049-1061

Townend I, Fletcher C, Knappen M, Rossington K (2011) A review of salt marsh dynamics. Water Environment Journal 25:477-488

van der Meijden R (2005) Heukels' Flora van Nederland, 23rd edn. Noordhoff Uitgevers, Groningen/Houten, the Netherlands

van Loon-Steensma JM, Slim PA, Decuyper M, Hu Z (2014) Salt-marsh erosion and restoration in relation to flood protection on the Wadden Sea barrier island Terschelling. Journal of Coastal Conservation 18: 415-430

van Loon-Steensma JM, Hu Z, Slim PA (2016) Modelled impact of vegetation heterogeneity and salt-marsh zonation on wave damping. Journal of Coastal Research 32:241-252

van Rooijen AA, McCall RT, van Thiel de Vries JSM, van Dongeren AR, Reniers AJHM, Roelvink JA (2016) Modeling the effect of wavevegetation interaction on wave setup. Journal of Geophysical Research, Oceans 121:4341-4359

van Veelen TJ, Fairchild TP, Reeve DE, Karunarathna H (2020) Experimental study on vegetation flexibility as control parameter for wave damping and velocity structure. Coastal Engineering 157:103648

Vuik V, Jonkman SN, Borsje BW, Suzuki T (2016) Nature-based flood protection: the efficiency of vegetated foreshores for reducing wave loads on coastal dikes. Coastal Engineering 116:42-56

Wang A, Gao S, Jia J (2006) Impact of the cord-grass Spartina alterniflora on sedimentary and morphological evolution of tidal salt marshes on the Jiangsu coast, China. Acta Oceanologica Sinica 25:32-42

Watson EB, Oczkowski AJ, Wigand C, Hanson AR, Davey EW, Crosby SC, Johnson RL, Andrews HM (2014) Nutrient enrichment and precipitation changes do not enhance resiliency of salt marshes to sea level rise in the northeastern U.S. Climatic Change 125:501-509

Wood N, Hine AC (2007) Spatial trends in marsh sediment deposition within a microtidal creek system, Waccasassa Bay, Florida. Journal of Coastal Research 23:823-833

Yang SL (1999a) Sedimentation on a growing intertidal island in the Yangtze River mouth. Estuarine, Coastal and Shelf Science 49: $401-410$

Yang SL (1999b) Tidal wetland sedimentation in the Yangtze Delta. Journal of Coastal Research 15:1091-1099

Yang SL, Eisma D, Ding PX (2000) Sedimentary processes on an estuarine marsh island within the turbidity maximum zone of the Yangtze River mouth. Geo-Marine Letters 20:87-92

Yang SL, Li H, Ysebaert T, Bouma TJ, Zhang WX, Wang YY, Li P, Li M, Ding PX (2008) Spatial and temporal variations in sediment grain size in tidal wetlands, Yangtze Delta: on the role of physical and biotic controls. Estuarine, Coastal and Shelf Science 77:657671

Yang SL, Shi BW, Bouma TJ, Ysebaert T, Luo XX (2012) Wave attenuation at a salt marsh margin: a case study of an exposed coast on the Yangtze estuary. Estuaries and Coasts 35:169-182

Ysebaert T, Yang SL, Zhang L, He Q, Bouma TJ, Herman PMJ (2011) Wave attenuation by two contrasting ecosystem engineering salt marsh macrophytes in the intertidal pioneer zone. Wetlands 31 : $1043-1054$

Publisher's Note Springer Nature remains neutral with regard to jurisdictional claims in published maps and institutional affiliations. 